\title{
Ecosystem Based Adaptation (EbA) \& Engineering Options (EOs) as a Solution for Climate Change induced Flood Hazard in Ajgada Village of Udayapur District, Nepal
}

\author{
Mr. Anjan Kumar Phoju ${ }^{1}$, Dr. Dinesh Chandra Devkota ${ }^{2}$, Mr. Tej Kumar Shrestha ${ }^{3 *}$, Mr. \\ Pawan Paudyal ${ }^{4}$, Ms. Sharmila Bajracharya ${ }^{5}$ \\ ${ }^{I}$ Senior Program/M\&E Officer, IDS-Nepal \\ ${ }^{2}$ Visiting Professor, CDES TU and Advisor IDS-Nepal \\ ${ }^{3}$ Faculty, Khwopa College, Dekocha, Bhaktapur \& Managing Director, Lumbini Environmental Services Pvt. Ltd. \\ ${ }^{4}$ Program Coordinator, Lumbini Environmental Services Pvt. Ltd. \\ ${ }^{5}$ Environment \& Social Analyst, Dolma Advisors Pvt. Ltd.
}

*Corresponding Author: Mr. Tej Kumar Shrestha, Faculty, Khwopa College, Dekocha, Bhaktapur \& Managing Director, Lumbini Environmental Services Pvt. Ltd.

\begin{abstract}
Nepal is particularly susceptible to climate-related disasters and experiences frequently landslides, debris flow and floods because of its varied topography and geological characteristics, together with torrential rain during the monsoon season. Today, there is need of finding better options to adapt with the effect of climate change. This research is based on a case study of Ksedi River catchment, Ajgada village of Hadiya in Udayapur district of Nepal, tries to demonstrate the best options for dealing with flood for making sustainability with long-term benefits. This research recommends Ecosystem based Adaptation and Engineering Options that are feasible in the village and watershed area to reduce the flood impacts. It is recommended for reforestation of upland forest areas, prioritization of adaptation options to receive maximum benefits and further detail study of EbA considering Payment of Ecosystem Services.
\end{abstract}

Keywords: Climate Change, Ecosystem based Adaptation, Engineering Options

\section{INTRODUCTION}

Climate change seriously affects every livelihood dimension of people in least developed countries like Nepal. Among them, poor and marginalized people with few livelihood options are often the most vulnerable to climate hazards such as floods and droughts (IPPC, 2007). Out of 170 countries in the Climate Change Vulnerability Index (CCVI) ranked over the next 30 years, Nepal is ranked 4th by Maplecraft (2012). Terai regions of Nepal are very much famous with vulnerable. In rainy season, floods affect various parts of the Terai every year. In Terai, floods wipe out most of the agricultural land, houses build near the banks of river and lives. Ecosystem Based Adaptation (EbA) is the use of biodiversity and ecosystem services as part of an overall adaptation strategy to help people to adapt to the adverse effects of climate change (CBD, 2009 and WB, 2009). Engineering Options are controlled disruption of natural process by using man-made structures. Engineering is the applied science of acquiring and applying knowledge to design, analysis, and/or construction of works for practical purposes (Science Daily).

The term loss and damage appeared in the United Nations Framework Convention on Climate Change (UNFCCC) at COP 13 in 2007, in Bali considering disaster risk reduction strategies and means to address loss and damage associated with climate change impacts in vulnerable countries (Loss and Damage in vulnerable countries initiative, 2012). Loss and damage were recognized as a separate concept from adaptation in 2008, when the alliance of small island states (AOSIS) proposed a MultiWindow Mechanism to address and finance which was followed by the UNFCCC work program on loss and damage in 2010 with Warsaw International Mechanism on Loss and Damage in 2013. Frequent floods are one of the recurrent natural disasters which has affect Nepal. 
There is an increasing trend of disaster occurring from flood hazards. Floods that have occurred in major rivers in recent years show that they have broken the record for the biggest floods over the past 50 years in many cases. The existing capacity to cope with and adapt to climate-induced hazards is very low. The human and economic losses faced every year clearly show how the country is unable to respond effectively (MoPE, 2017). Water-induced disasters like floods, landslides and avalanches cause nearly $29 \%$ of the annual deaths and $43 \%$ of the annual property losses from all disasters in Nepal (Khanal, 2005). Climate change triggered flood are causing significant human and economic loss and such devastation will further accelerate in future as the average temperature in Nepal is increasing. Nepal is frequently affected by water-induced disasters. Floods are the major climate related hazard in the country (GoN, 2010), through landslides and droughts are also significant.

Water induced disaster of varying intensity and magnitude affect various parts of Nepal regularly. Most floods occur in Nepal during monsoon seasons due to heavy rainfall. Terai regions of Nepal are vulnerable to floods during the rainy season. Udayapur has experienced the impact of climate change with increasing temperature and irregular precipitation (Practical Action, 2009). The major problem of Ksedi river is high sedimentation rate with high rate of deforestation.

The general objective of this study is to explore the literature and understanding on the issue of Ecosystem-based Adaptation and Engineering Option. More specifically, this research intends to identify the vulnerability due to flood, assess the status of EbAs and EOs for flooding in Ajgada village \& explore people's perception towards EbAs and EOs for flood.

\subsection{Study Site}

Ajgada is an area with a small group of hamlets in Hadiya VDC lies at latitude of $26.4600^{\circ}$ and longitude of $86.5120^{\circ}$ and has an elevation of 120 meters above sea level. The two main rivers in Udayapur reported increased rate of flooding and region of Udayapur in Nepal was found to be particularly susceptible to increasing severe floods and vulnerable to the impact of climate change (Bauer, 2013).

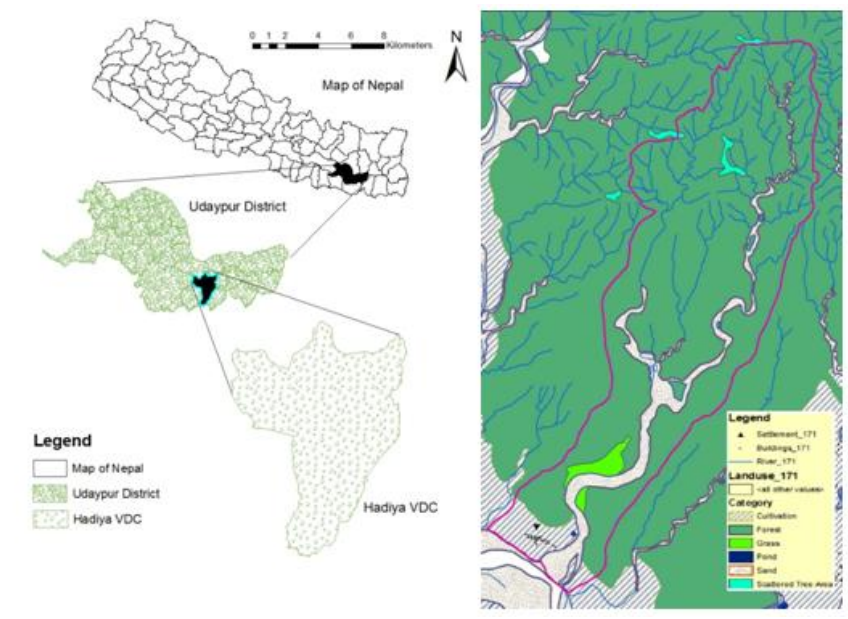

Figure1. Map Showing Study Area (L) and Ksedi River Watershed and Ajgada Village (R)

Terai-Churia range covers $23 \%$ of surface area and $48 \%$ of population which has high impacts and implications of climate change due to seasonal river, originate from Churia range with irregular high flood and debris flow (high sedimentation) causing inundation of communities in rainy season. Ajgada village is an area with a small group of dwelling/ hamlets in Hadiya VDC. Ajagad lies in Trijuga basin in North and Churia range in Southern part. People migrated from various districts to Ajgada from 2039 B.S. The main rivers in the study site originate from the southern Siwalik range, also known as the Churia Hills, which lie in the 300 - 1500 meters above sea level and are composed of steep slope and weak, unconsolidated bedrock.

\section{METHODOLOGY}

The people centered approach of this study was primarily based on a household survey with quantitative and qualitative assessments of 52 household respondents. Beyond the survey, key informant interview, focus group discussions and secondary sources provided further information that 
was used to validate survey findings. The questionnaire consists of socio demographic data, loss and damage data and perception of vulnerability with their recommendations for future action.

\section{RESULT}

People of Ajgada village lives close to Ksedi river. $15 \mathrm{HHs}$ of Dalits and $45 \mathrm{HHs}$ of disadvantages group residing in village living proximity to river make these communities expose to the risk of being affected by flooding. The condition of houses in the study area is fragile which displays vulnerability to flooding.

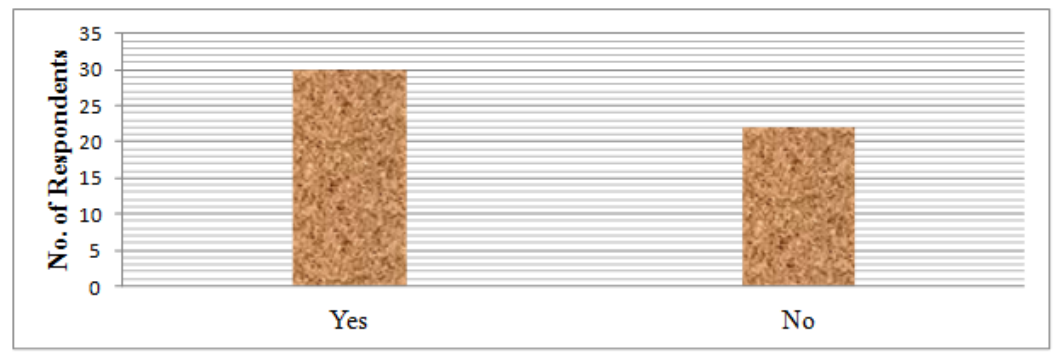

Figure2. Loss of Agricultural Land from Flood

In the Ajgada Village the most occurring natural disaster is flood and most of their agricultural land and settlement lies in either side of the river. In the household survey, 62\% respondents land is affected by flood, which shows their land is being degraded at the time of flooding. An agricultural field in the Ajgada village is situated along the alluvial plain of seasonal rivers. When flood occur, floods inundate fields, deposit sand, damage paddy land and sometimes sweep field away entirely. Group discussion with community members clearly indicated that poor, marginalized, women, children and the disabled are most vulnerable to climate change impacts as they have less capacity to cope up with such unavoidable situations.

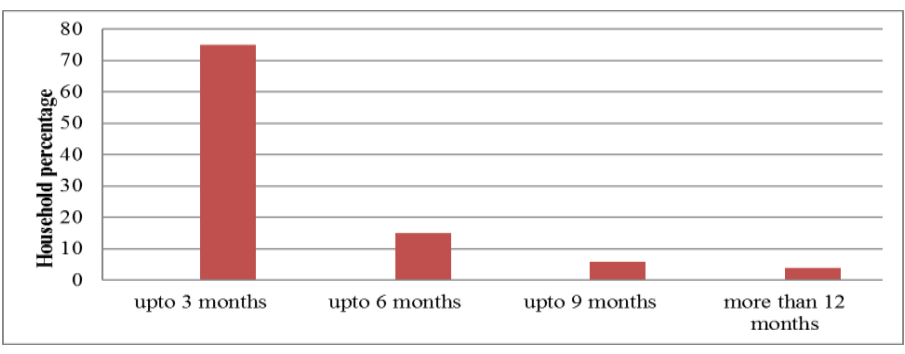

Figure3. Food Security of Agricultural Dependent Household

Weather directly affects food security via crop production. Agricultural fields in the study area are situated along the alluvial plain. The local agricultural land is clearly not producing surpluses. From the households' survey, it was found that most of households are agricultural dependent economy and their crop production is just sufficient for three months. When river to violate their banks and inundate fields during the rainy season and these farmers are facing endemic issues of food security. Floods damage topsoil which reduces soil fertility and organic matter declining returns from land and loss able to accumulate food. And, the agricultural productivity in the locality is declining.

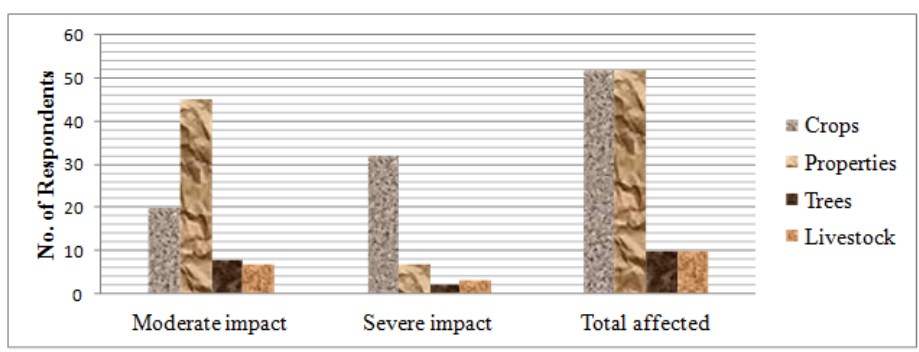

Figure4. Flood Affected Household by Impact Type

From the household survey, there are adverse effects of flooding on their households. They most commonly cited impact of flooding was on crop production. $62 \%$ were reported that "severe" effects of flooding on their crops and 38\% noted "moderate" effects of flooding on their crops. Each flood event affects the agricultural land because the level and cultivated land is almost equivalent. 


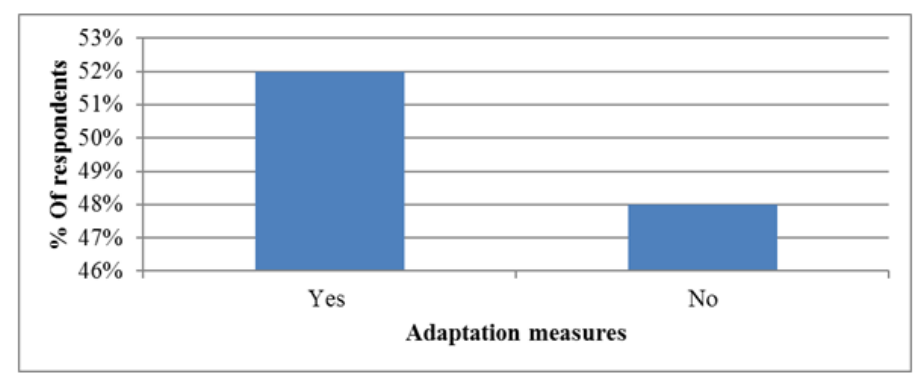

Figure5. Measures Adopted by Household to Impact Type

In the study area, households adopt a variety of preventive measures to adopt flooding including planting plants, construction of gabion walls and bamboo weirs, bamboo fences and sand dykes. In case of coping and adaptation strategies $48 \%$ households did not prepare anything to prevent flood in their residential area or agricultural land. 52\% households were preparing anything to prevent flood in their residential area or agricultural land. But again, they were being affected because of $48 \%$ households are not doing anything to prevent flood.

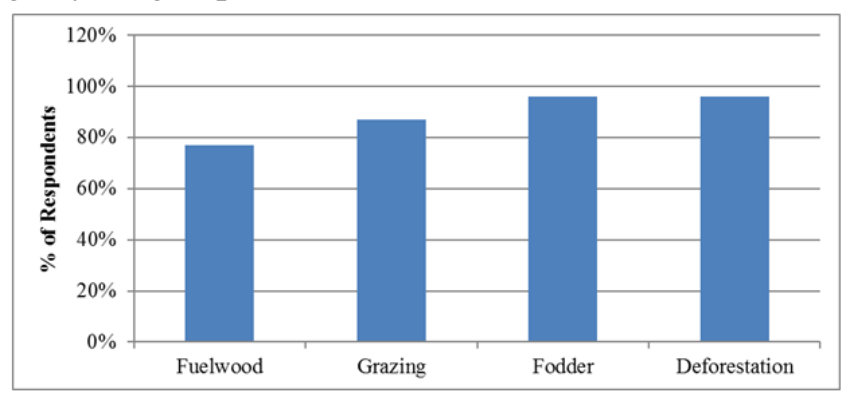

Figure6. Present Scenario of EbAs

The community forest user groups have planted different types of plants like Bamboo, Simal, Sal, Kans but proper care is not provided. $96 \%$ of local people respondents there is high rate of deforestation and nominal construction of gabion walls, but it has been buried due to high rate of sedimentation. Due to high sedimentation riverbed and settlement level is almost in same level. The implementation of BbAs and EOs can be done in two phases, implementation in Ksedi watershed area is the first phase and village protection are the second phase.

Potential EbA options recommended by the locals are:

- Establishment of nursery and Plantation of local tree species, Broom grass, bamboo

- Grazing management

- Forest fire management

- Bamboo wattle

Recommended Engineering Options:

- Gully check dam

- River check dam

- Embankments

- Conservation Ponds

- Spur

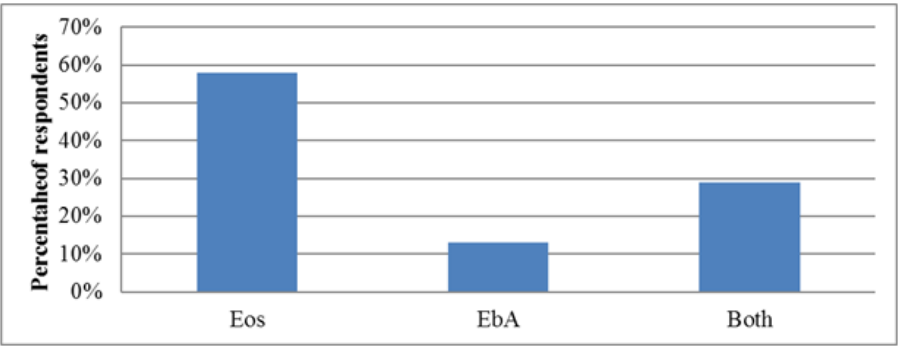

Figure7. Perception of Local People on EbAs and Eos 
$58 \%$ local people focused on implementing engineering approaches rather than ecosystem-based approaches because it has immediate result but EbA approach is time consuming ie, entire watershed management is essential for sustainability. 13\% respondents focused on implementing ecosystembased approaches to reduce flood risk and $29 \%$ focused on hybrid technology on implementing to reduce flood risk. But based on source of income $77 \%$ respondents prefer EOs as an implementing mechanism to prevent the residing area, people having medium source of income $13 \%$ prefer EbA as an implementing mechanism and only $10 \%$ prefer hybrid technology as an implementing mechanism having higher source of income.

\section{DISCUSSION}

The study area is vulnerable to water-induced disaster. The settlement area and agricultural land is more sensitive to flooding because of high sediments. The riverbed lies above the settlement and agricultural land. Due to the closeness to the river and using fewer adapting measures, those areas are vulnerable to flooding. $80 \%$ of people depend on agriculture as their source of income whereas $62 \%$ people land lies near to the river. The crop yield of major cereals is decreasing than the previous year. Climate change is projected to have significant impacts on farming households. For flood related disaster, the use of indigenous knowledge especially in the use of local plants like bamboo, filling sand in sack can provide cost-effective methods of flooding solutions.

The adaptation can be ecosystem-based approach or engineering approach or both i.e., hybrid approach. From the life span of ecosystem-based approach and engineering approach it enhances hybrid technique for sustainable management of watershed. In the very first year, the strength of engineering approach will be high but as time passes away strength also decrease. But in the case of ecosystem-based approach it is just reverse ie, in very first phase the strength will be low but increases as time pass away i.e., plant becomes stronger with time as vegetation established.

\section{CONCLUSION}

Ksedi River watershed and entire Ajgada village is vulnerable to flood and overflowing rivers caused sedimentation which also severely affect crops and livestock, where the crops were either partially or completely submerged and the livestock suffered from a lack of fodder availability. The Dalit's settlement of this village is most vulnerable as living close to the Ksedi River. The lack of proper predisaster awareness techniques prevents adequate preparation procedures and loss and damage due to extreme flooding can almost be perceived as an unavoidable consequence. And, the civilians were requested not to reside in low-lying areas or near rivers, such a request is unfeasible as most of the people reside in such vulnerable areas and migrated from other places.

Besides loss of life, houses and land, people in the area suffered a wide range of impacts from the flooding, particularly on their mental health and livelihoods. Households that are in direct need of support for survival and recovery would often end up receiving lower amounts of compensation than better-off households.

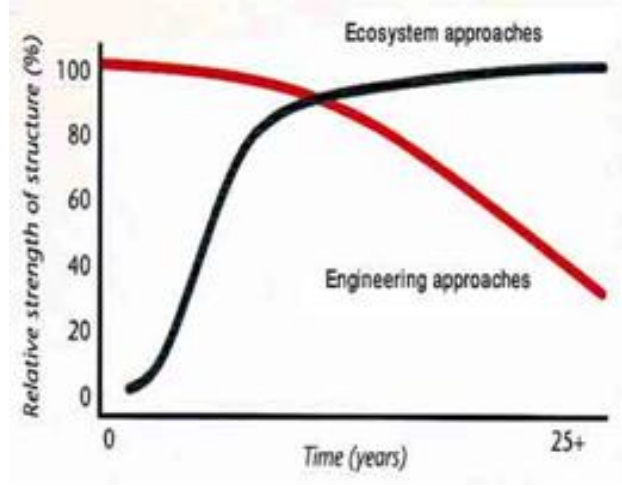

Figure8. Life Span of EbAs and EOs

Limited number of gabion walls is present, and it has been submerged by high sedimentation. People residing in Ajgada village focus in Engineering options which will be efficient in flood and erosion control in initial stage. But, with comparing the standard life span hybrid technology i.e., EbAs and EOs will be better and sustainable for controlling flooding as adaptation measures. 


\section{RECOMMENDATIONS}

- Enhance collaboration and communication within as well as between government agencies and external research organization;

- Enhance public awareness about climate change;

- Reforestation of upland forest areas, plantation along riverbed and its management as well as management of rangeland;

- Target engineering options to protect settlement and agricultural lands;

- Prioritize adaptation options to receive maximum benefits by the community;

- Encourage EbAs and EOs joint effort to protect village and ecosystem;

- Further detail study of EbA considering payment of ecosystem is recommended;

\section{ACKNOWLEDGEMENT}

The researcher wishes to thank Niraula's Family residing in Hadiya for supporting in this study. Researcher wish to acknowledged Ms. Saphalta Chukkan and others for their generous support in fieldwork.

\section{REFERENCES}

[1] Bauer, K. (2013). Loss and damage from flooding in Udayapur District, Nepal. Loss and Damage in Vulnerable Countries Initiative, case study report. Bonn: United Nations University Institute for Environment and Human Security

[2] CBD (2009). Connecting Biodiversity and Climate Change Mitigation and Adaptation: Report of the Second Ad Hoc Technical Expert Group on Biodiversity and Climate Change. Montreal, Technical Series No. 41, 126 pages

[3] GoN (2010). National Adaptation Programme of Action (NAPA). Government of Nepal, Ministry of Environment, September 2010

[4] IPCC (2007). Climate Change 2007: Synthesis Report. An assessment of the Intergovernmental Panel on Climate Change

[5] Khanal, N.R. (2005). Water induced disasters: Case studies from the Nepal Himalayas. In: Landschaftsökologie und Umweltforschung 48 (Proceedings of International Conference on Hydrology of Mountain Environments, Berchtesgaden, Germany, 27 Sept-1 Oct 2004 48) [Herrmann, A. (ed.)], Braunschweig, pp. 179-188

[6] Maplecroft (2010). Maplecroft: South Asia most at risk from climate change, Scandinavia safest, [Online].Retrievedon17Aug,2012from

http://www.preventionweb.net/english/professional/news/v.php.id=16004

[7] MoEST (2010). Climate Change Vulnerability Mapping for Nepal

[8] Practical Action (2009). Temporal and Spatial Variability of Climate Change over Nepal (1976-2005)

[9] UNFCCC (2012). Ecosystem - based Adaptation (Online). Retrieved from http://unfccc.int/4159.php

[10] Warner, K. K. van der Geest. (2013). "Loss and damage from climate change: Local-level evidence from nine vulnerable countries." Int. J Global Warming 5(4): 367-386.

Citation: Mr. Tej Kumar Shrestha, et.al, "Ecosystem Based Adaptation (EbA) \& Engineering Options (EOs) as a Solution for Climate Change induced Flood Hazard in Ajgada Village of Udayapur District, Nepal", International Journal of Research in Environmental Science (IJRES), vol. 5, no. 3, pp. 10-15, 2019. Available: DOI: http://dx.doi.org/10.20431/2454-9444.0503002

Copyright: (0) 2019 Authors. This is an open-access article distributed under the terms of the Creative Commons Attribution License, which permits unrestricted use, distribution, and reproduction in any medium, provided the original author and source are credited. 